\title{
Bond strength of glass fiber posts cemented with bulk-fill flowable composite resin
}

\author{
Victor da Mota Martins, Camila Ferreira Silva, Lorena Mendes Almeida, Marcella Silva de Paula, \\ Murilo de Sousa Menezes and Paulo Cesar Freitas Santos-Filho * (1)
}

\author{
${ }^{*}$ Correspondence: \\ paulocesarfs@ufu.br \\ Department of Restorative \\ Dentistry and Dental \\ Materials, Dentistry School, \\ Biomechanics Research \\ Group, School of Dentistry, \\ Federal University \\ of Uberlândia, Avenida \\ Pará, 1720, Bloco 4L, Anexo \\ A, Campus Umuarama, \\ Uberlândia, Minas Gerais \\ 38400-902, Brazil
}

\begin{abstract}
This study evaluated the adhesive bond strength of glass fiber posts cemented with bulk-fill flowable resin in endodontically treated teeth, and the results were compared with those of glass fiber posts cemented with resin cement. Forty bovine incisor roots were selected and randomly divided into 2 groups $(n=20)$. The external surfaces of the roots were coated with a molding material. The canals were prepared, and then the fiber posts (Whitepost no. 2, FGM) were cemented with either resin cement (Allcem, FGM) $(n=20)$ or bulk-fill flowable resin (Opus Bulk Fill, FGM) $(n=20)$. Ten roots $(n=10)$ of each material were subjected to push-out and pull-out tests (EMIC DL 2000, Brazil) under compressive and tensile loading, respectively; a $50 \mathrm{~N}$ load cell and a constant crosshead speed of $0.5 \mathrm{~mm} / \mathrm{min}$ was used for both tests. The testing data were analyzed using multifactorial analyses of variance two-way ANOVA and the Tukey test $(a=0.05)$. Two skilled operators determined the failure modes of the samples using a stereomicroscope at $40 \times$ magnification with a $2.5 \mathrm{D}$ analysis. For push-out bond strength, there were no statistically significant differences between the root thirds in the bulk-fill flowable resin group and those in the resin cement group $(p=0.536)$. However, there were statistically significant differences $(p<0.001)$ among the root thirds within the same group. For pull-out bond strength, there were no statistically significant differences between the groups $(p=0.739)$. Therefore, the bulk-fill flowable resin exhibited similar results to those of the resin cement from the same manufacturer in terms of the cementation of glass fiber posts, which suggests that bulk-fill flowable resin is a suitable alternative material for cementation.
\end{abstract}

Keywords: Glass fiber post, Bulk-fill resin, Push-out, Pull-out, Bond strength

\section{Introduction}

Endodontically treated teeth have a high incidence of biomechanical failure, which has been the target of several studies [1-3] that seek to understand different mechanical properties of endodontically treated teeth and relate the resistance to failure with the quality of the remaining dental structure and the kind of material used to build up the cavity.

Studies have shown that glass fiber posts (GFPs) provide support, reduce root fracture risks, and enhance retention, thereby providing enhanced stress dissipation [4, 5]. However, an adhesive layer is needed to improve the mechanical behavior of glass fiber posts within dentin $[6,7]$.

(c) The Author(s) 2019. This article is distributed under the terms of the Creative Commons Attribution 4.0 International License (http://creativecommons.org/licenses/by/4.0/), which permits unrestricted use, distribution, and reproduction in any medium, provided you give appropriate credit to the original author(s) and the source, provide a link to the Creative Commons license, and indicate if changes were made. 
Adhesive cementation protocols have shown that deeper portions in the adhesive layer cannot be penetrated by light, which can negatively influence the bond strength to the root dentin. Nevertheless, the optical properties of glass fiber posts can improve the degree of conversion in the root up to a depth of $8 \mathrm{~mm}$ [8]. Moreover, the literature has recommended and demonstrated the use of resin cement with an adhesive system as an option for cementation [6, 7].

In 2012, Giovannetti et al. performed some cementation protocols with a flowable composite originally proposed for bulk filling posterior restorations [9]. Their study showed that bulk-fill flowable composites produced better results regarding cavity configurations (C-factors) to build up class I or II cavities [10] than conventional composite resins; in deep cavities, bulk-fill flowable composites exhibited satisfactory bond strength with the remaining structure [11].

The thickness of the incremental layer was tested to validate the correct curing depths of different bulk-fill composite resins. As a flowable resin, bulk-fill composite resins exhibit stable results [12], which enables rehabilitation possibilities, rebuilds structural loss in single incremental layers, allows cavities with depths of approximately $6 \mathrm{~mm}$ to be filled [11, 12], and facilitates core build up and glass fiber post cementation [13].

The fillers present within bulk-fill resins are composed of small particles that allow transillumination through the material, which activates the initiator system that absorbs the light and converts monomers into polymers [13]. Bulk-fill flowable resin may provide low stress behavior to glass fiber post cementation [9].

The aim of this study was to evaluate the adhesive bond strength of glass fiber posts cemented with bulk-fill flowable resin in endodontically treated teeth and then compare the results with those of glass fiber posts cemented with resin cement. In the view of this aim, the null hypotheses were that the bulk-fill flowable resin exhibits the same behavior as resin cement in push-out bond strength and pull-out bond strength.

\section{Materials and methods}

\section{Specimen preparation}

Forty roots of bovine incisors from older animals with similar size and shape were selected from extracted teeth under sanitary evaluation by the Ministry of Health and consent of the responsible veterinarian. The teeth were stored in a buffered aqueous solution of $0.2 \%$ thymol. The teeth were cleaned with periodontal curettes (Duflex, Juiz de Fora, MG, Brazil) and submitted to prophylaxis with pumice paste and water, and then the teeth were stored in distilled water and refrigerated at $4{ }^{\circ} \mathrm{C}$. The teeth were sectioned with a diamond disc (\# 7020-KG Sorensen, Cotia, SP, Brazil) under a constant water flow; the root section were $15 \mathrm{~mm}$. The selected teeth were randomly divided into two different groups: one group $(\mathrm{n}=20)$ for micro push-out testing and failure mode analysis and another group $(\mathrm{n}=20)$ for pull-out testing.

The root canal preparation procedure comprised the sequential use of \#2, \#3 and \#4 Gates Glidden drills (Malleifer, Dentsply, Petrópolis, RJ, Brazil). The \#2 Gates Glidden drill was used across the entire root canal, the \#3 Gates Glidden drill was used to reach the apical third without crossing it, and the \#4 Gates Glidden drill was used only in the extension where the relief was taken. An irrigation solution of $1 \%$ sodium hypochlorite and saline solution was used between each gate with final irrigation performed with $17 \%$ 
EDTA. The root canal was filled with gutta-percha cones (Dentsply, Petrópolis, RJ, Brazil) and calcium hydroxide-based shutter cement (Sealer 26, Dentsply, Petrópolis, RJ, Brazil) using the lateral condensation technique. After obturation of the root canal, the relief of the canal was performed with Paiva pluggers in an extension of $10 \mathrm{~mm}$, leaving $5 \mathrm{~mm}$ of remaining obturation material. Wide \#5 Gates Glidden drills were used (Dentsply, Petrópolis, RJ, Brazil) to prepare the canal for receiving the posts at the corresponding relief extension. Forty $(n=40)$ glass fiber posts were selected (Whitepost no. 2, FGM; Joinville; SC; Brazil) with a coronary diameter of $2.0 \mathrm{~mm}$, a middle diameter of $1.8 \mathrm{~mm}$ and an apical diameter of $1.05 \mathrm{~mm}$, and these posts received surface treatment prior to cementation. The post surface was treated with $35 \%$ hydrogen peroxide (Whiteness HP Maxx; FGM, Joinville; SC; Brazil) under friction for $1 \mathrm{~min}$, washed for the same period of time and then dried with air jets [14]. Then, the posts were treated with silane agent (Prosil, FGM Produtos Odontológicos, Joinville, SC, Brazil) for $1 \mathrm{~min}$. Root canal cleaning was performed by irrigation with distilled water and moisture control with absorbent paper tips (Tanari, Manacapuru, AM, Brazil).

The roots were covered with a molding material (Perfil, Coltene, Rio de Janeiro, RJ, Brazil) to prevent environmental light from influencing the light curing process. In the resin cement $(\mathrm{RC})$ group $(\mathrm{n}=20)$, a resin cement (Allcem Dual, FGM, Joinville, SC, Brazil) was used. This resin cement required previous treatments, such as $37 \%$ phosphoric acid (Condac 37\%, FGM, Joinville, SC, Brazil) for $15 \mathrm{~s}$, and an adhesive system (AMBAR Universal, FGM, Joinville, SC, Brazil), which was light-cured on the dentin for $20 \mathrm{~s}$ with an LED unit (Radii-Cal, SDI, Australia) that had a light intensity of $800 \mathrm{~mW} / \mathrm{cm}^{2}$. A pretreated glass fiber post was inserted at same time as the resin cement, the excess resin cement was removed, and then the cement was chemically cured for 5 min under the application of a constant $500 \mathrm{~g}$ load on the glass fiber posts and light-cured for $20 \mathrm{~s}$ on each surface (occlusal, buccal, lingual, medial, and distal).

In the bulk-fill group (BF) (Opus Bulk Fill, FGM, Joinville, SC, Brazil) $(n=20), 37 \%$ phosphoric acid (Condac 37\%, FGM) was applied for $15 \mathrm{~s}$ followed by the application of the adhesive system (AMBAR Universal, FGM) within the dentin root, which was lightcured for $20 \mathrm{~s}$. Then, the bulk-fill flowable resin was applied within the root at the same time as the pretreated glass fiber post, the excess resin was removed and light-cured for $20 \mathrm{~s}$ on each surface (occlusal, buccal, lingual, medial, and distal).

\section{Push-out mechanical testing}

Ten samples from each group $(\mathrm{n}=10)$ were stored for 7 days in distilled water at $37^{\circ} \mathrm{C}$ prior to push-out mechanical testing. Each sample was fixed to an acrylic plate $(4.0 \mathrm{~cm} \times 3.0 \mathrm{~cm} \times 0.4 \mathrm{~cm})$ attached with heated Godiva (Godiva Exata, DFL, Jacarepaguá, RJ, Brasil) and sectioned in six slices in the region of the cemented glass fiber post with a double-face diamond disc $\left(4^{\prime \prime} \times 0.12 \times 0.12\right.$, Extec, Enfield, CT, USA), which was attached to a precision cutter machine (Isomet 1000, Buehler, Lake Bluff, IL, USA) and cooled by water. The sectioning process produced two $1 \mathrm{~mm}$ thick slices for each third (cervical, middle and apical thirds) of the root.

To perform the push-out mechanical tests, three different tip sizes (1.3, 1.15 and $0.97 \mathrm{~mm}$ ) associated with three bases $(2.5,2.2$ and $2.0 \mathrm{~mm}$ ) were used. For testing on the cervical third, a $2.5 \mathrm{~mm}$ base and a $1.3 \mathrm{~mm}$ tip were used. For testing on the middle 
third, a $2.2 \mathrm{~mm}$ base and a $1.15 \mathrm{~mm}$ tip were used. For testing on the apical third, a $2.0 \mathrm{~mm}$ base and a $0.97 \mathrm{~mm}$ tip were used. The varied diameters of the tips and bases were used to introduce shear stress along the bonding interface according to the conical shape.

The push-out mechanical tests were performed with a universal mechanical testing machine (EMIC DL 2000, São José dos Pinhais, Brazil) containing a $50 \mathrm{~N}$ load cell. The slices were positioned at the center of the post coinciding with the whole of the metal base and the applicator tip, and then the slices were subjected to a compressive load with a constant crosshead speed of $0.5 \mathrm{~mm} / \mathrm{min}$ in the apex/crown direction, avoiding any mechanical obstruction due to the conical shape of the fiber post, until displacement of the glass fiber post occurred. The maximum load at failure was recorded in Newtons $(\mathrm{N})$ and converted to megapascals $(\mathrm{MPa})$ by dividing the applied load by the bonded area (A), which was calculated with the following formula: $A=\pi(r 1+R 2) \sqrt{r 1}-R 2) 2+h 2$, where $\pi$ is a constant with a value of approximately $3.14 ; \mathrm{r}$ and $\mathrm{R}$ are the smallest and the largest radii of the cross-sectioned tapered post, respectively; and $\mathrm{h}$ is the thickness of the section.

\section{Failure mode classification}

Two skilled operators determined the failure modes with a stereomicroscope at $40 \times$ magnification (Mitutoyo, Tokyo, Japan) with a 2.5D analysis. The fractured specimens were analyzed with a stereoscope (Leica) to determine where the failure occurred. In this study, failures were classified into 5 different types: [(1) adhesive failure between the post and resin cement; (2) adhesive failure between the resin cement and root dentin; (3) cohesive failure within the fiber post; (4) cohesive failure within the dentin; and (5) mixed failure with the resin cement partially covering the post surface].

\section{Pull-out mechanical testing}

Ten samples from each group $(n=10)$ were prepared and stored for 7 days in distilled water at $37^{\circ} \mathrm{C}$ prior to pull-out mechanical testing. A $10 \mathrm{~mm}$ portion of each fiber post was kept outside the larger diameter, and instead of pushing the post, it was fixed in a device and pulled until the post of the root canal was pulled out. To perform the pullout mechanical tests, a predefined base was used in the Biomaterials, Biomechanics and Molecular Biology Research Center (CPBio-UFU) to introduce uniform tensile stresses along the interface. A composite resin support was adapted at the end of the glass fiber post, which served as a socket for the device to perform the test. This configuration was assembled in a mechanical test machine (EMIC DL 2000, São José dos Pinhais, Brazil) containing a $50 \mathrm{~N}$ load cell and loaded at a constant crosshead speed of $0.5 \mathrm{~mm} / \mathrm{min}$. The adhesive strength (in $\mathrm{MPa}$ ) was calculated in the push-out tests.

\section{Statistical analysis of the data}

The data were initially analyzed for detection of normal distribution and homogeneity using the Kolmogorov-Smirnov test. The values that allowed the use of parametric analysis were analyzed using multifactorial analyses of variance two-way ANOVA at a significance level of $5 \%$. The Tukey test $(\alpha=0.05)$ was used to determine significant 
differences between the groups. The analyses were carried out using Sigma Plot 12 (Systat Software Inc., USA).

\section{Results}

For the micro push-out bond strength, the bulk-fill flowable and resin cement groups did not show a statistically significant difference between the material groups $(\mathrm{p}=0.536)$. However, there was a statistically significant difference $(\mathrm{p}<0.001)$ between root regions, wherein the values in the cervical third were significantly higher than those in the middle and apical regions (Table 1). The bulk-fill group failure mode was primarily Type 5 failure in the apical third, which was mixed failure with the resin cement partially covering the post surface, followed by Type 2 failure in the cervical region, which was adhesive failure between the resin cement and root dentin (Table 2). The most frequent failure mode in the resin cement group was adhesive failure between the resin cement and root dentin in the middle third, followed by similar failures in the apical and cervical thirds (Table 3). For micro pull-out bond strength, the difference in the mean values of the two groups was insufficient to reject the possibility that the difference was due to random sampling variability, and there was not a statistically significant difference between the groups $(\mathrm{p}=0.739)$ (Table 4$)$.

\section{Discussion}

Although bulk-fill composite resin had not previously been indicated for use in the cementation of glass fiber posts, one study showed presented protocols for testing bulkfill flowable resin for this purpose [9]. With this approach, the null hypotheses were accepted because the bulk-fill flowable resin exhibited similar bond strength results as the resin cement in push-out and pull-out tests. No differences in bond strength were identified between the resin cement and bulk-fill composite resin; however, note that

Table 1 Mean push-out bond strength-MPa [standard deviation]

\begin{tabular}{lll}
\hline & Bulk-fill flow & Allcem \\
\hline Cervical third & $5.50[3.15] \mathrm{Aa}$ & $5.27[2.36] \mathrm{Aa}$ \\
Middle third & $1.86[1.53] \mathrm{Ab}$ & $2.73[2.22] \mathrm{Ab}$ \\
Apical third & $1.35[2.18] \mathrm{Ab}$ & $2.87[1.73] \mathrm{Ab}$ \\
\hline
\end{tabular}

Bond strength of glass fiber posts cemented with bulk-fill flowable resin and resin cement determined by push-out tests. The mean values followed by the same uppercase letter in each row and the same lowercase letter in each column are not significantly different according to the results of two-way ANOVA $(p<0.05)$. The Tukey test was necessary to determine significant differences between groups

Table 2 Push-out test failure mode distribution for each root third in the bulk-fill resin group $(n=20)$

\begin{tabular}{lccllr}
\hline & Type 1 & Type 2 & Type 3 & Type 4 & Type 5 \\
\hline Cervical & $2(10 \%)$ & $11(55 \%)$ & $1(5 \%)$ & $0(0 \%)$ & $6(30 \%)$ \\
Middle & $5(25 \%)$ & $5(25 \%)$ & $2(10 \%)$ & $0(0 \%)$ & $8(40 \%)$ \\
Apical & $2(10 \%)$ & $2(10 \%)$ & $0(0 \%)$ & $0(0 \%)$ & $16(80 \%)$ \\
\hline
\end{tabular}


Table 3 Push-out test failure mode distribution for each root third in the resin cement group $(n=20)$

\begin{tabular}{llllll}
\hline & Type 1 & Type 2 & Type 3 & Type 4 & Type 5 \\
\hline Cervical & $3(15 \%)$ & $10(50 \%)$ & $3(15 \%)$ & $0(0 \%)$ & $4(20 \%)$ \\
Middle & $1(5 \%)$ & $13(65 \%)$ & $1(5 \%)$ & $0(0 \%)$ & $5(25 \%)$ \\
Apical & $0(0 \%)$ & $11(55 \%)$ & $0(0 \%)$ & $0(0 \%)$ & $9(45 \%)$ \\
\hline
\end{tabular}

The failure modes of glass fiber post cemented with bulk-fill flowable resin and resin cement were classified into 5 different types: (1) adhesive failure between the post and resin cement; (2) adhesive failure between the resin cement and root dentin; (3) cohesive failure within the fiber post; (4) cohesive failure within the dentin; and (5) mixed failure with the resin cement partially covering the post surface

Table 4 Mean pull-out bond strength-MPa [standard deviation]

\begin{tabular}{lr}
\hline Bulk-fill flow & \multicolumn{1}{c}{ Allcem } \\
\hline $1.305[0.615] \mathrm{A}$ & $1.230[0.335] \mathrm{A}$ \\
\hline
\end{tabular}

Bond strength of glass fiber posts cemented with bulk-fill flowable resin and resin cement determined by pull-out tests. The means are not significantly different according to the results of the $t$ test $(p<0.05)$

bulk-fill composite resin still cannot be classified as a cement, even when used for this purpose. The mechanical testing results showed similar behavior in both materials, wherein the primary differences in the root regions of both groups were found in the middle third and the apical third.

In the rehabilitation of endodontically treated teeth with GFPs, cementing agents increase the contact between the dental structure and the restorative material, and the thickness showed significant influences on the bond strength. If the layer was excessively thick or thin, retention of the GFP significantly decreased [6, 7]. The results shown in this research might be explained by the excellent contact between the glass fiber post and root canal walls.

A number of authors performed mechanical property tests of endodontically treated teeth and found that flowable composite resin exhibited a low elastic modulus, low stress behavior polymerization and good marginal integrity without compromising the depth of cure $[9,15]$, which is indicated by the luting process of glass fiber posts with flowable resin. Furthermore, the light transmission could be affected by the material composition [16].

Bulk-fill flow resins have a high degree of polymerization because their translucency allows deeper penetration of the polymerization light and because of the addition of new photoinitiators, such as benzoyl germanium derivatives, which significantly increase the reactivity of the monomers and the depth of cure [17]. With these factors, the cementation of GFPs with bulk-fill flow can be performed in deep cavities once the material is manufactured to work in situations to further facilitate the light curing process.

Differences in the degree of conversion between resin-based luting agents might also have a role in their mechanical strength. A recent study showed that the dual-cured resin cement had significantly higher flexural properties than light-cured resin cement, which is explained by the higher filler loading of the catalyst paste compared to the base paste; however, the additional curing certainly contributed to the improved strength by increasing the conversion and polymer crosslinking $[18,19]$. These results can also be 
observed in the micro push-out bond strength test, wherein a small difference with no significant relevance exists in the middle and apical thirds.

The protocol for aging or storing the samples was related to a protocol reported by Sarkis-Onofre [20], wherein samples were stored in distilled water for 7 days at $37^{\circ} \mathrm{C}$ prior to testing. This storage time showed that the bond strength did not seem to be influenced by the aging protocol [21].

The results can be explained because etch-and-rinse adhesives require an accurate technique to control the dentin moisture and proper infiltration of the adhesive solution into the root canal, which is a procedure that might be considered critical and might affect post retention. The etch-and-rinse approach has also been reported to leave a nonencapsulated collagen zone beneath the hybrid layer, which could interfere with the longevity of the bonds [20].

The difference between the results of the three root regions might suggest that the light curing process influenced the bulk-fill group in the middle and apical thirds and illustrate the compensation by the chemical polymerization in the same thirds in the resin cement group. When comparing each third, it can be seen that the cervical third exhibited a better bond strength than the other thirds because of the greater light exposure. However, the middle third exhibited a slight difference in the bond strength between the groups because the irradiance could not efficiently reach the middle and apical thirds due the depth. The bond strength in the apical third of the resin cement group was twice as high as that of the bulk-fill group, which shows the importance of independent polymerization from the light curing unit [13].

In general, there was a higher incidence of adhesive failure between the resin cement and root dentin and mixed failures than other failure modes. Within the bulk-fill group, the most prevalent category was "mixed failure with resin cement partially covering the post surface" in the apical third, whereas in the cement resin group, the most frequent failure mode was "adhesive failure between the resin cement and root dentin" in the middle third. Regardless of the group, there was a higher incidence of adhesive failure between the resin cement and root dentin and mixed failures than the other failure modes, suggesting that dentin might have influenced adhesion. The $2.5 \mathrm{D}$ analysis allowed a detailed identification of failures and described the spot visualized on the dentin-adhesive interface [22].

This study showed some limitations, such as the protocol for adhesion and the type of bulk-fill resin tested, and suggests future studies that could be performed with different adhesives, bulk-fill flowable resins, conventional composites, cure depths, material translucency and cavity configurations.

\section{Conclusions}

Bulk-fill flow composite resin exhibited similar results to those of resin cement from the same manufacturer in terms of the cementation of glass fiber posts, which suggests that bulk-fill flowable resin is a suitable alternative material for cementation.

Abbreviations

n: number; 2.5D: 2.5 -dimensional; ${ }^{\circ} \mathrm{C}$ : celsius; $\mathrm{mm}$ : millimeter; $\mathrm{mm} / \mathrm{min}$ : millimeter/minute; GFP: glass fiber post; RC: resin cement; BF: bulk fill; N: Newtons. 


\section{Acknowledgements}

FGM for donating the material tested.

\section{Authors' contributions}

VMM, CFS and LMA designed this study. LMA prepared and tested the samples. MSP analyzed and interpreted the data. MSM reviewed the manuscript. PSFSF was a mentor and corresponding author. VMM was the primary author of the manuscript. All authors read and approved the final manuscript.

\section{Funding}

Support Funding Agency/Grant Number: PIVICMG2017SAU039.

This study was financed in part by the Coordenação de Aperfeiçoamento de Pessoal de Nível Superior-Brasil (CAPES) Finance Code 001.

\section{Availability of data and materials}

All data generated or analyzed during this study are included in this manuscript.

\section{Competing interests}

The authors declare that they have no competing interests.

Received: 20 February 2019 Accepted: 23 May 2019

Published online: 04 June 2019

\section{References}

1. Moris ICM, Moscardini CA, Moura LKB, Silva-Sousa YTC, Gomes EA. Evaluation of stress distribution in endodontically weakened teeth restored with different crown materials: 3D-FEA analysis. Braz Dent J. 2017;28(6):715-9. https://doi. org/10.1590/0103-6440201701829.

2. Santos-Filho PC, Castro CG, Silva GR, Campos RE, Soares CJ. Effects of post system and length on the strain and fracture resistance of root filled bovine teeth. Int Endod J. 2008;41(6):493-501. https://doi.org/10.111 1/j.1365-2591.2008.01383.x.

3. Faria AC, Rodrigues RC, de Almeida Antunes RP, de Mattos Mda G, Ribeiro RF. Endodontically treated teeth: characteristics and considerations to restore them. J Prosthodont Res. 2011;55(2):69-74. https://doi.org/10.1016/j. jpor.2010.07.003.

4. Corrêa G, Brondani LP, Wandscher VF, Pereira GKR, Valandro LF, Bergoli CD. Influence of remaining coronal thickness and height on biomechanical behavior of endodontically treated teeth: survival rates, load to fracture and finite element analysis. J Appl Oral Sci. 2018;26:e20170313. https://doi.org/10.1590/1678-7757-2017-0313.

5. Franco EB, Lins do Valle A, Pompéia Fraga de Almeida AL, Rubo JH, Pereira JR. Fracture resistance of endodontically treated teeth restored with glass fiber posts of different lengths. J Prosthet Dent. 2014;111(1):30-4. https://doi. org/10.1016/j.prosdent.2013.09.013.

6. Rodrigues RV, Sampaio CS, Pacheco RR, Pascon FM, Puppin-Rontani RM, Giannini M. Influence of adhesive cementation systems on the bond strength of relined fiber posts to root dentin. J Prosthet Dent. 2017;4:493-9. https://doi. org/10.1016/j.prosdent.2017.01.006

7. Bergoli CD, Brondani LP, Wandscher VF, Pereira G, Cenci MS, Pereira-Cenci T, et al. A multicenter randomized double-blind controlled clinical trial of fiber post cementation strategies. Oper Dent. 2018;43(2):128-35. https://doi. org/10.2341/16-278-c.

8. Galhano GA, de Melo RM, Barbosa SH, Zamboni SC, Bottino MA, Scotti R. Evaluation of light transmission through translucent and opaque posts. Oper Dent. 2008;33(3):321-4. https://doi.org/10.2341/07-93.

9. Giovannetti A, Goracci C, Vichi A, Chieffi N, Polimeni A, Ferrari M. Post retentive ability of a new resin composite with low stress behaviour. J Dent. 2012;40(4):322-8. https://doi.org/10.1016/j.jdent.2012.01.007.

10. Sagsoz O, Ilday NO, Karatas O, Cayabatmaz M, Parlak H, Olmez MH, et al. The bond strength of highly filled flowable composites placed in two different configuration factors. J Conserv Dent. 2016;19(1):21-5. https://doi. org/10.4103/0972-0707.173188.

11. Van Ende A, De Munck J, Van Landuyt KL, Poitevin A, Peumans M, Van Meerbeek B. Bulk-filling of high C-factor posterior cavities: effect on adhesion to cavity-bottom dentin. Dent Mater. 2013;29(3):269-77. https://doi.org/10.1016/j. dental.2012.11.002.

12. Flury S, Peutzfeldt A, Lussi A. Influence of increment thickness on microhardness and dentin bond strength of bulk fill resin composites. Dent Mater. 2014;30(10):1104-12. https://doi.org/10.1016/j.dental.2014.07.001.

13. Ilie N, Keßler A, Durner J. Influence of various irradiation processes on the mechanical properties and polymerisation kinetics of bulk-fill resin based composites. J Dent. 2013. https://doi.org/10.1016/j.jdent.2013.05.008.

14. Menezes MS, Faria-e-Silva AL, Silva FP, Reis GR, Soares CJ, Stape TH, et al. Etching a fiber post surface with highconcentration bleaching agents. Oper Dent. 2014;39(1):E16-21. https://doi.org/10.2341/12-270-I.

15. Roggendorf MJ, Krämer N, Appelt A, Naumann M, Frankenberger R. Marginal quality of flowable 4-mm base vs. conventionally layered resin composite. J Dent. 2011;39(10):643-7. https://doi.org/10.1016/j.jdent.2011.07.004.

16. Fronza BM, Ayres A, Pacheco RR, Rueggeberg FA, Dias C, Giannini M. Characterization of inorganic filler content, mechanical properties, and light transmission of bulk-fill resin composites. Oper Dent. 2017:42(4):445-55. https:// doi.org/10.2341/16-024-l.

17. Lagocka R, Jakubowska K, Chlubek D, BuczkowskaRadlinska J. Elution study of unreacted TEGDMA from bulk-fill composite (SDRTM Dentsply) using HPLC. Adv Med Sci. 2015;60:191-8. https://doi.org/10.1016/j.advms.2015.02.003.

18. Spazzin AO, Oliveira OA, Guarda GB, Leal FB, Correr SL, Moraes RR. Strengthening of porcelain provided by resin cements and flowable composites. Oper Dent. 2016;41(2):179-88. https://doi.org/10.2341/15-025-I. 
19. Marcos RM, Kinder GR, Alfredo E, Quaranta T, Correr GM, Cunha LF, et al. Influence of the resin cement thickness on the push-out bond strength of glass fiber posts. Braz Dent. 2016;J27(5):592-8. https://doi.org/10.1590/0103-64402 01600886.

20. Sarkis-Onofre R, Skupien JA, Cenci MS, Moraes RR, Pereira-Cenci T. The role of resin cement on bond strength of glass-fiber posts luted into root canals: a systematic review and meta-analysis of in vitro studies. Oper Dent. 2014;39(1):E31-44. https://doi.org/10.2341/13-070-lit.

21. Leme AA, Pinho AL, de Gonçalves L, Correr-Sobrinho L, Sinhoreti MA. Effects of silane application on luting fiber posts using self-adhesive resin cement. J Adhes Dent. 2013;15(3):269-74. https://doi.org/10.3290/j.jad.a28881.

22. Da Silva NR, Aguiar GC, Rodrigues Mde P, Bicalho AA, Soares PB, Veríssimo C, Soares CJ. Effect of resin cement porosity on retention of glass-fiber posts to root dentin: an experimental and finite element analysis. Braz Dent J. 2015;26(6):630-6. https://doi.org/10.1590/0103-6440201300589.

\section{Publisher's Note}

Springer Nature remains neutral with regard to jurisdictional claims in published maps and institutional affiliations.

\section{Submit your manuscript to a SpringerOpen ${ }^{\circ}$} journal and benefit from:

- Convenient online submission

- Rigorous peer review

- Open access: articles freely available online

- High visibility within the field

Retaining the copyright to your article

Submit your next manuscript at $\gg$ springeropen.com 